Guide to Fluorescence Literature - Volume 2

By R. A. Passwater. IFI/Plenum - New York, Washington and London 1970. Bound volume with cover; $17 \times 26 \mathrm{~cm}$; 369 pages. Author and Subject Index. Price US $\$ 22.50$.

As the author points out in the Preface, " a bibliography is a collection of references, but a guide to the literature must be much more ". In fact, it represents the solution of theoretical and analytical problems.

This second volume continues the scheme of Volume 1, although the various articles are now presented under six major classifications: Analytical, organic; Analytical, inorganic; Theoretical; Immunofluorescence; Phosphors; and Addendum.

The references are grouped by year, from 1964 to 1968, and arranged alphabetically by first author; the author and subject index further facilitate the location of a specific reference.

\section{Control of Human Fertility}

Edited by G.I.M. Swyer. British Medical Bulletin, 26, 1, 1970. Medical Department of the British Council, London. Paperback; $28 \times 22$ $\mathrm{cm}$. 98 pages including numerous tables and illustrations. Price $£ 2.00$ (US $\$ 6.00$ ).

Introduced by Sir Alan Parkes, the following subjects are dealt with: Hypothalamus and control of ovulation (G. W. Harris and F. Naftolin); Pheromones (H. M. Bruce); Evidence for luteolysin (L.E.A. Rowson); Induction of ovulation with gonadotropins (A. C. Crooke); Clomiphene (P.M.F. Bishop); Effectiveness and risks of birth-control methods (D.M. Potts and G.I.M. Swyer); Rare adverse effects of systemic contraceptives (Richard Doll and M.P. Vessey); Developments in steroidal hormonal contraception (Arnold Klopper); Postcoital contraception (C.W. Emmens); IUD's in women and other mammals ( $P$. Eckstein); Surgical methods of fertility control (P.C. Steptoe); Termination of pregnancy (D. M. Potts); Immunology of conception and pregnancy (R.G. Edwards); Antispermatogenic agents (Harold Jackson); Hormone production in the mammalian testis (Dennis Lacy and A. Juliet Pettitt).
La Dyade Coniugale - Étude Sociologique (The Conjugal Dyad - A sociological study)

By Pierre de Bie, Karel Dobbelaere, Claire Leplae, Jacques Piel (Louvain). Les Éditions Vie Ouvrière - Bruxelles 1968. Paperback; $18 \times 24$ $\mathrm{cm} ; 137$ pages including numerous tables. Price FB 200 (approx. US \$ 4.00).

Introduced by Reuben Hill, Director, Minnesota Family Study Center, and one of the organizers of the research reported here, this booklet is subdivided into three main parts: (1) Structure of domestic tasks and of power of decision in the conjugal dyad (by Claire Leplae); (2) Communication between husband and wife and conjugal satisfaction (by Jacques Piel); and (3) Children (by Karel Dobbelaere). A general conclusion (by Pierre de Bie) and a methodological appendix complete this research work which throws more light on the behavior of the average couple in the industrialized society.

Les Autres Mondes - Les Peuples et Leur Culture

(Other Worlds - The peoples and their culture)

By M.A. Robert (pseudonym of a working group in human sciences). Les Editions Vie Ouvrière - Bruxelles 1968. Paperback; $18 \times 18$ $\mathrm{cm} ; 216$ pages +8 tables of pictures. Price FB 220 (approx. US \$ 4.50).

The relativity of social life, in the so different behavior and mentality both among and within societies, is systematically analyzed in the light of numberless examples and with respect to (1) the basic social culture, (2) the process of acculturation and education, and (3) social and cultural changes and evolution.

\section{Océanographie Médicale \\ (Medical Oceanography)}

By M. and J. Aubert. Gauthier-Villars - Paris 1969. Bound volume; $16 \times 24 \mathrm{~cm}$; 298 pages; 1 colored and 86 black-and-white illustrations; 35 tables; 3 maps. Price not indicated.

After a description of the various ecologic problems and the organization of medical nceanographic research, sea is presented from the two opposite viewpoints of its precious 